\title{
Distancing sedation in end-of-life care from physician- assisted suicide and euthanasia
}

\author{
Tze Ling Gwendoline Beatrice $\underline{S o h}^{1,2}$, FRACP, FAChPM, Lalit Kumar Radha Krishna ${ }^{1,2,3}$, MA Med Edu, PhD, \\ Shin Wei $\underline{\text { Sim }}^{1}$, MBBS, Alethea Chung Peng $\underline{Y e e}^{1,2}$, MRCP, FAMS
}

\begin{abstract}
Lipuma equates continuous sedation until death (CSD) to physician-assisted suicide/euthanasia (PAS/E) based on the premise that iatrogenic unconsciousness negates social function and, thus, personhood, leaving a patient effectively 'dead'. Others have extrapolated upon this position further, to suggest that any use of sedation and/or opioids at the end of life would be analogous to CSD and thus tantamount to PAS/E. These posits sit diametrically opposite to standard end-of-life care practices. This paper will refute Lipuma's position and the posits borne from it. We first show that prevailing end-of-life care guidelines require proportional and monitored use of sedatives and/or opioids to attenuate fears that the use of such treatment could hasten death. These guidelines also classify CSD as a last resort treatment, employed only when symptoms prove intractable, and not amenable to all standard treatment options. Furthermore, CSD is applied only when deemed appropriate by a multidisciplinary palliative medicine team. We also show that empirical data based on local views of personhood will discount concerns that iatrogenic unconsciousness is tantamount to a loss of personhood and death.
\end{abstract}

Keywords: continuous sedation until death, palliative care, personhood, Ring Theory of Personhood, terminal sedation

\section{INTRODUCTION}

Continuous sedation until death (CSD) and physician-assisted suicide/euthanasia (PAS/E) are two distinct treatments. However, vagaries in defining CSD have blurred this distinction. Terms such as 'terminal sedation', 'sedation for intractable distress in the imminently dying', 'end-of-life sedation', 'palliative sedation' (PS), 'sedation in the final phase', 'palliative sedation therapy' and ' $\mathrm{CSD}^{\prime}$ ' have contributed to the misunderstanding of the indications and role of CSD, and promulgated a continued association with the practice of PAS/E. ${ }^{(1,2)}$ Variability in the determination of key requirements for the valid application of CSD, such as diagnoses of intolerable and refractory suffering, prognosis of less than two weeks, the consent process leading up to the application of CSD, and dosing schedules and drug formulary for CSD have further muddied the lines between CSD and PAS/E.

Till now, concerns about CSD have largely been in the realm of ethical deliberation within the local palliative medicine setting, with Krishna and colleagues revealing no specific incidences of its use within the local setting. ${ }^{(3-5)}$ However, a recent clinical encounter by nurses working in a palliative medicine unit in Singapore has changed the complexion of these discussions. Quoting Lipuma's paper on CSD, (2) family members expressed grave concerns when healthcare professionals attempted to treat a terminally ill patient's agitation with antipsychotics. While considered standard practice in light of the failure of nonpharmacological means, based upon Lipuma's position that sedation in end-of-life care, ostensibly till death, was euthanasia, the family felt that the healthcare professionals were effectively 'killing' their loved one.
The above incident raised two considerations: (a) the need to clarify the misconceptions set out by Lipuma's position on CSD and PAS/E; and (b) the need to differentiate 'routine' use of sedation in end-of-life care from the practice of CSD. In this article, we focus on the first point. Krishna and Ho addressed the second point in a recent article. ${ }^{(6)}$

\section{LIPUMA'S POSITION}

Lipuma ${ }^{(2)}$ believes that the application of CSD, defined as deep and continuous sedation applied with the specific intention of providing "pain management rather than hastening the death of the patient" by rendering a patient "permanently unconscious until complete biological death", is tantamount to "hastening death" ${ }^{\prime(1,2)}$ Furthermore, Lipuma believes that the main indication for CSD, which is to circumnavigate "the devil's choice" of having to choose between allowing the continuation of intractable suffering among terminally ill patients and the equally morally abhorrent act of assisting in the suicide of these patients, is a misrepresentation of facts. ${ }^{(2)}$ He suggests that rendering irreversible loss of consciousness, ostensibly till death, eliminates "what is meaningful to human life", negates personhood and renders a patient effectively dead. He also believes this iatrogenic induction of 'social death' and negation of personhood is tantamount to killing a patient and, thereby, indistinguishable from PAS/E. ${ }^{(2)}$

Lipuma utilises a combination of empirical data on the current practice of sedation in end-of-life care, philosophical reviews on the issue of personhood and the value of human life, case studies, and a New York Times front page story on CSD to confront the three main objections to his position. ${ }^{(2,7,8)}$ First, he posits that

${ }^{1}$ Division of Palliative Medicine, National Cancer Centre Singapore, ${ }^{2}$ Duke-NUS Medical School, ${ }^{3}$ Centre for Biomedical Ethics, Yong Loo Lin School of Medicine, National University of Singapore, Singapore

Correspondence: Dr Lalit Kumar Radha Krishna, Senior Consultant, Division of Palliative Medicine, National Cancer Centre Singapore, 11 Hospital Drive, Singapore 169610. lalit.krishna@singhealth.com.sg 
"death should not be defined in terms of higher brain function" to address the objection that CSD patients retained higher brain function and thus could not be considered brain dead as a result of the application of CSD. ${ }^{(2)}$ Second, Lipuma attempts to show that the "reversibility criterion", emphasising that the effects of CSD are reversible, is misguided. He does so by suggesting that a reversal of sedation would return the patient to a state of awareness of their intractable suffering, which would be morally and clinically unacceptable. ${ }^{(2)}$ Third, to overturn the notion "that by double effect, the intention of CSD is pain management, not killing", Lipuma suggests that the routine cessation of hydration that accompanies CSD leaves deeply sedated patients incapable of feeding themselves, which effectively crystallises an underlying intention to the contrary. ${ }^{(2)}$

\section{Adoption of higher brain definitions of death}

Lipuma argues that the presence of higher brain function bestows moral worth and meaning to a human life. ${ }^{(2)}$ According to him, the induction of deep, irreversible unconsciousness, which leads to "dying an experiential death, that is, chemically and purposefully simulating the condition of one who is dead, based on higher brain functioning", denies the patient of a meaningful existence, particularly when there is little chance that cognitive function can be regained. ${ }^{(2)}$ He opines that it is higher brain function that gives a person a meaningful life, while lesser brain function merely represents a physiological function that keeps the body alive, bereft of meaningful existence. To 'correct' this implausibility and to accurately classify such patients as 'dead' despite still possessing functioning cardiovascular and respiratory systems, Lipuma proffers the "higher brain (neocortical) definitions of deat $h^{\prime \prime}$. As a result, patients on CSD would effectively be classified as 'dead', given that they had no chance of recovering their higher brain function. ${ }^{(2)}$

\section{Argument on reversibility criterion}

At the crux of Lipuma's earlier point is the issue of the irreversibility of iatrogenic-induced deep sedation in CSD. He explained that the cessation of sedation would simply result in the resumption of suffering ostensibly till death, which would be antithetical to good end-of-life care and the goals of care. As a result, Lipuma believed that CSD could not be reversed, thus leaving the 'reversibility criterion' without merit. ${ }^{(2)}$

\section{Argument on double effect}

A common defence of CSD has come from the invocation of the doctrine of double effect (DDE). ${ }^{(9)}$ The DDE is seen to contain the following four principles: (1) the nature of the act must be 'good' or at least 'neutral'; (2) the 'good' effect cannot be brought about by the 'bad' effect; (3) the act must be proportional to the exigencies of the situation; and (4) the intention behind the act must be morally 'good' or at least 'neutral'..$^{(10,11)}$ Lipuma, however, contends that the induction of CSD would be in breach of three of the four central principles of the DDE. ${ }^{(12-14)}$ The first is that the 'nature of the act' is neither 'good' nor 'neutral' given its associations with bringing about death. ${ }^{(12-14)}$ The second condition within the DDE is also violated, as success of CSD can only come about through the 'bad' outcome; in other words, relief of suffering is only brought about by the induction of deep and irreversible unconsciousness, which is tantamount to 'death'. ${ }^{(12-14)}$ The final condition of the DDE is infringed, as the good effect of symptom amelioration is realised only by bringing about the foreseen ill effects of deep irreversible unconsciousness. ${ }^{(12-14)}$ Lipuma argued that the application of CSD in the knowledge that it is irreversible and that "eliminating consciousness is in effect the same as inducing a state that is functionally identical with neocortical death" crystallises the wish to hasten death. ${ }^{(2)}$

\section{Condensing Lipuma's position into the practical triumvirate and personhood triad}

Beyond the three arguments raised, a closer scrutiny of Lipuma's position reveals the presence of six considerations - three interconnected factors that relate to medical practice issues, referred to as the "triumvirate of interlinked practical considerations (or practical triumvirate)", and three interrelated considerations that pertain to personhood, referred to as the "triad of personhoodrelated considerations (or personhood triad)". For Lipuma's position to be accepted, both the personhood triad and practical triumvirate require universal acceptance in their own right.

The personhood triad arises from the belief that conscious function defines "a meaningful way for a human being to exist or to be considered alive". (2) The personhood triad is composed of the beliefs that: (a) personhood pivots upon the presence of conscious function; (b) an irreversible loss of consciousness leads to an irretrievable loss of personhood; and (c) a loss of personhood negates 'what is meaningful to human life' and renders a patient dead. ${ }^{(2)}$

The practical triumvirate requires a homogenous practice of CSD in order to highlight the similarity of this practice with PAS/E. (2) The practical triumvirate is made up of the requirements that: (a) there is a common understanding of the practice, goals and indications of CSD; (b) the practice of CSD is applied in a consistent manner; and (c) when applied, CSD leaves little chance for the re-establishment of personhood. ${ }^{(2)}$

\section{REBUTTAL OF LIPUMA'S POSITION}

The present study suggests that each element within the personhood triad and practical triumvirate are problematic. Discrediting each element will ultimately refute and discredit Lipuma's posit. We begin with a review of the elements within the practical triumvirate.

\section{THE PRACTICAL TRIUMVIRATE}

Underpinning the adoption of the practice described as CSD lies Lipuma's wish to limit discussion to a very particular practice that is seen to be most akin to PAS/E. ${ }^{(2)}$ The term CSD is drawn from a study by Rys et al, ${ }^{(15)}$ which Lipuma believes offers "the most accurate characterisation of what the therapy actually entails and implies". ${ }^{2,15)}$ There is no explanation as to why such credence is given to Rys et al's review over more established or systematic studies on the subject. ${ }^{(15-18)}$ In truth, the nature of the 
sampling used in Rys et al's study ${ }^{(15)}$ limits its credibility to being nothing more than a study of the 'opinion sections of medical and nursing journals' and 'grey literature' published from 1966 to 2009 , rather than an authoritative review on the subject, as Lipuma hopes. ${ }^{(15)}$

The inclusion criteria used in Rys et al's study ultimately undermines Lipuma's position that there is a common understanding and consistent practice of CSD, as does Rys et al's admission that the term CSD "highlight[s] the lack of agreement among clinicians on this topic ${ }^{\prime \prime}{ }^{(15)}$ Careful scrutiny of the paper by Rys et al reveals variances in the understanding and practice of CSD, including: (a) drug selection and their indications for use; (b) the provision of hydration and nutrition in end-of-life care; (c) the deliberative process underpinning the authorisation for the application of CSD; (d) the manner that treatment was applied and understanding of the term CSD; (e) the central role of proportionality of response and the overall goals of CSD; and (f) the higher brain function definition of death.

Central to Lipuma's efforts to equate CSD with PAS/E is a consistent practice of CSD. We discuss each variance in turn in order to disprove this notion. Yet, it is not our intention to defend the term CSD but rather, the concept that it stands for. We will show that the practice that Lipuma refers to is both defunct and unlike Krishna's modern, locally conceived concept of continuous deep palliative sedation, which is described as: "the proportional and monitored induction of deep continuous sedation for the amelioration of all forms of intractable physical, psychological, and existential suffering. The guidelines state that this must follow holistic, multi-professional assessment of the patient's condition to affirm that suffering is in fact intractable, that the anticipated prognosis is less than two weeks, and that the application of such an intervention is in the patient's best interests. The intent of this procedure is to circumnavigate awareness of suffering through the maintenance of deep levels of sedation in a manner that is consistent with prevailing guidelines and clinical, professional, and legal standards. This procedure is monitored and overseen by a multidisciplinary team (MDT) to ensure accountability, transparency, and justifiability of actions and to make certain that life is not intentionally abbreviated."(19)

\section{Primary sedative agents in CSD}

On the issue of drug selection, Lipuma's attention is focused on the employment of barbiturates as the primary agent in inducing CSD, given that its use for induction of deep sedation is both risky and disproportional to the exigencies of the situation. Lipuma's motive for doing so is to crystallise the intention to hasten death. To lend credence to these efforts, he turns to Lo and Rubenfeld's account of the terminal sedation of Mrs B, ${ }^{(7)}$ a 49 -year-old woman with metastatic breast cancer who was admitted to the hospital for pain control of bone metastasis. ${ }^{(7)}$ To ameliorate her intractable suffering, Lipuma highlights the use of barbiturates to induce CSD in this patient.

A closer scrutiny of Lo and Rubenfeld's article reveals that Mrs B received barbiturates to induce deep sedation only after the failure of treatments such as hydromorphone, fentanyl, morphine, celecoxib, amitriptyline, lorazepam and a course of radiotherapy to alleviate her symptoms, and as a result of dose-limiting side effects. ${ }^{(7)}$ Furthermore, the authors added that phenobarbital was only employed as "midazolam was not permitted on the unit where the patient was receiving care" ${ }^{\prime(7)}$ Our scrutiny of Mrs B's case further reaffirms the following cardinal features of acceptable sedative use in end-of-life care:

1. Last resort: CSD is a treatment of last resort when symptoms remain intractable and alternative treatment options are exhausted. 'Risky' options are only administered when 'safer' means have been exhausted or unavailable, and suffering persists.

2. Safety: CSD is employed only when there are effective means of ensuring safety and titration of these drugs. Lo and Rubenfeld state that a significant consideration for the employment of CSD is "that the site of care provides an appropriate level of nursing care and monitoring" ${ }^{(7)}$ In Mrs B's case, treatment was titrated under monitoring to ensure her life was not jeopardised. Data would suggest that Lo and Rubenfeld's use of focused and proportional application of sedatives may even prolong life in a minority of cases. . $^{(20-22)}$

3. Choice of agent: contrary to Lipuma's assertions, a review of regnant palliative care formularies and PS guidelines reveals that barbiturates are rarely employed in the induction of deep and continuous sedation in end-of-life care. In all recent PS guidelines, barbiturates do not feature either as first- or second-line agents in the application of CSD. Benzodiazepines are preferred to barbiturates primarily as result of their well-studied effects, rapid onset of action, short half-life and high therapeutic index, as well as greater physician experience in their employ, and the presence of an antidote, should the need arise.(7) The overall intent of safeguarding the patient is exemplified by the choice of a medication with an easily accessible antidote. Thus, should adverse reactions (such as respiratory depression) develop, prompt and appropriate remedial action can be taken to reverse the effects of the benzodiazepine and maintain the safety of the patient. This safety-first approach serves to refute Lipuma's objection to the reversibility criterion, i.e. that the effects of sedation cannot be reversed. . $^{(7,23)}$ Indeed, a practical interpretation of the reversibility criterion may be that the effects of sedation can be reversed in light of potential risks to the patient's life, with the emphasis on the goals of CSD to ameliorate suffering safely and without the abbreviation of life..$^{(7,23,24)}$

4. Impact of sedation: the impact of sedation on the cognitive abilities and conscious levels of most patients on which CSD is applied appears to be overstated. Claessens et al and Hui et al reveal that most patients tend to experience varying levels of consciousness as part of the natural dying process, which tends to occur 7-10 days prior to death. ${ }^{(25,26)}$ This point is important given that Kohara et $\mathrm{al}^{(27)}$ and Mercadante et $\mathrm{al}^{(28)}$ both showed that CSD tends to be applied 2-3.4 days before death, suggesting that most patients would already be experiencing varying 
levels of sedation and cognitive impairment before CSD is applied. ${ }^{(25-28)}$

5. Variations in level of consciousness to sedation: Lipuma's key argument is that CSD results in the negation of higher brain function, which he believes is integral to a meaningful existence. ${ }^{(2)}$ To advance such a stance, sedation applied in CSD must be shown to consistently suppress consciousness. Porzio et al report that midazolam-induced CSD fails to maintain deep continuous sedation in about a third of patients. ${ }^{(29)}$ Barbato's use of bispectral index monitors also found variations in levels of consciousness in terminally ill, sedated patients. ${ }^{(30)}$ In many cases, patients revealed some awareness or showed only minimal sedation. Before we highlight the stark implications of these findings upon Lipuma's higher brain function definition of death, we acknowledge that it is not midazolam that Lipuma discusses, but barbiturates. However, given that such practice is largely defunct, it is more clinically relevant to comment upon the effects of midazolam upon sedation, and the study by Barbato has shown that higher brain function is not entirely suppressed as a result of this practice. ${ }^{(30)}$

\section{Clinically assisted nutrition and hydration}

Mrs B's case ${ }^{(7)}$ serves as a platform to discuss another of Lipuma's assertions - the routine cessation of clinically assisted nutrition and hydration $(\mathrm{CANH})$ upon application of CSD. Lipuma believes that ceasing $\mathrm{CANH}$ in an unconscious patient leaves them susceptible to death by dehydration, which he asserts, uncovers the true intentions of the physician in applying CSD. ${ }^{(2)}$ Such assertions highlight a number of misconceptions regarding the prevailing practices of sedation in end-of-life care. A review of the prevailing frameworks of PS shows that the provision of $\mathrm{CANH}$ is assessed on a case-by-case basis, thereby ensuring that clinical and psychosocial factors are given adequate consideration in each case. ${ }^{(31)}$ Such heterogeneity in the employment of $\mathrm{CANH}$ in CSD, which highlights the variance in CSD practices, as well as the disproving of the belief that $\mathrm{CANH}$ is routinely ceased, further erodes Lipuma's position. ${ }^{(31)}$

In truth, Lipuma's conjecture on the underlying intention of physicians in 'routinely' ceasing $\mathrm{CANH}$ highlights further misreading of clinical practices, as well as Lo and Rubenfeld's case; the authors clearly stated that the patient had "already stopped eating and would have died shortly even had they [CANH] been administered." ${ }^{\prime(7)}$

\section{Authorisation of treatment}

Lipuma's comparison between CSD and PAS/E also extends to the manner that CSD is authorised. His concerns pivot on two key issues: first, he likens the authorisation process of CSD to that of PAS/E, and second, he asserts that authorisation of CSD is a clinical decision bereft of psychosocial input and oversight, and hence, paves the way for a slippery slope to PAS/E. Lipuma posits that the adoption of either practice crystallises and equates the intentions of the clinicians to those underpinning PAS/E. ${ }^{(2)}$ Lipuma also suggests that authorisation for the application of
CSD in Mrs B's case was done upon request, in a manner similar to PAS/E. ${ }^{(2)}$ However, a review of Lo and Rubenfeld's original case presentation reveals that CSD was applied only when Mrs B's condition met the prerequisites for CSD set out within prevailing guidelines, rather than simply upon the request of the patient. ${ }^{(7)}$

Lipuma also uses the case of Mr Leo Oltzik, a mentally incompetent patient suffering from terminal agitation and dementia, congestive cardiac failure and kidney problems, as an example of CSD being applied surreptitiously with little involvement of the patient's family. ${ }^{(2,8)}$ Lipuma suggests that circumnavigation of familial involvement in this case, drawn from Hartocollis' 2009 New York Times article, ushers in concerns of a 'slippery slope' leading to PAS/E. Lipuma further asserts that lax oversight of the application of CSD compounds these concerns. $^{(2,7,8)}$

A closer scrutiny of Hartocollis' account, however, reveals that Lipuma's conclusions were misguided. ${ }^{(2,8)}$ There are also a number of concerns with regard to the way Lipuma has employed Hartocollis' account of Mr Oltzik's care. ${ }^{(2,8)}$ First, this was a newspaper article charting a medical encounter that reported the observations of a journalist who was neither part of the medical team nor likely to be privy to the circumstances and finer details of the case. Furthermore, the report did not meet the rigorous standards required for a case report published in most medical journals, and lacks critical clinical information and medical analysis. These concerns are amplified by Lipuma's paper, which omitted some critical information from the original newspaper report. ${ }^{(2,8)}$ Contrary to Lipuma's assertions that the decisions for CSD and cessation of CANH were made unilaterally and without the input of the family, Hartocollis' report clearly states that both Mrs Oltzik and her daughter were aware of and party to the decision to sedate the patient. ${ }^{(8)}$ Similar to Mrs B's case, CSD was applied to Mr Oltzik in keeping with the prevailing clinical guidelines for PS. ${ }^{(2)}$ These guidelines included a holistic review by a palliative care team and/or an independent review by a professional, a prognosis of death in less than two weeks, the presence of intractable suffering, exhaustion of all viable treatment options and the likelihood of continued suffering until death without the provision of CSD. ${ }^{(32,33)}$

It is also clear that simplistic inferences as to the intentions behind the application of CSD cannot be defined solely upon a review of the actions surrounding the employment of CSD or indeed, the cessation of CANH. Krishna and Capps argued that intentions must be seen upon a more holistic plane and within the specific confines of the particular case setting. ${ }^{(4)}$ The actions themselves must be taken in totality, and ought to take into account discussions and the decision-making process that preceded the action rather than be judged solely upon the 'final act'. Further, Krishna and Capps, and Krishna and Chin argue that delineation of the intentions that underpin clinical undertakings must be considered upon an evidence-based platform and in keeping with prevailing practice guidelines, legal frameworks and social expectations. ${ }^{(4,11,34)}$ Any digression from accepted practice must be clearly justified, documented and ideally carried out 
with the oversight of a multidisciplinary team, if concerns about the intentions of the clinicians are to remain above reproach. ${ }^{(4)}$

\section{Use of the term 'CSD'}

Any comment about the intentions of a clinician must be made upon a clear understanding of the practice being discussed. This is particularly evident in Lipuma's misreading of Rietjens et al's study concerning the opinions of nurses who had experience employing PAS/E and CSD. ${ }^{(18)}$ Lipuma suggests that nurses with experience employing PAS/E and CSD opined that there was little difference between the two interventions. ${ }^{(2,18)}$ Scrutiny of Rietjens et al's original paper reveals that only four of the 16 nurses interviewed reported concerns with the employment of CSD. ${ }^{(18)}$ Critically, the authors noted that these four nurses "had little experience with palliative sedation". ${ }^{(18)}$ This serves the further purpose of drawing attention to the poorly defined term employed by Lipuma to delineate the practice of sedation in end-of-life care. ${ }^{(2,18)}$ Later studies by Rietjens and colleagues reaffirm that underpinning the fears voiced by the four nurses in the 2007 study by Rietjens et al was a lack of clarity on the practice of CSD. ${ }^{(35,36)}$

\section{Proportionality and the overall goals of care}

A further abortive effort to aggregate CSD under the umbrella of PAS/E sees Lipuma suggesting that "[b]oth procedures are only successfully completed upon Mrs B's complete biological deat $h^{\prime \prime} .{ }^{(2)}$ Such a posit runs contrary to PS guidelines. ${ }^{(19)}$ Prevailing guidelines on PS pivot upon the principle of proportionality and the temperate and monitored employment of sedation. ${ }^{(4,34)}$ The endpoint of treatment is in fact the effective amelioration of diagnosed intractable suffering in the safest, most proportionate, effective and efficient means, using the lowest possible doses to do so. ${ }^{(4,34)}$ There is no desire to hasten death..$^{(8,4,34)}$

\section{The higher brain function definition of death}

The higher brain function definition of death, which Lipuma employs to proffer a new definition of death, straddles the practical triumvirate and personhood triad. According to this definition of death, any irreversible suppression of conscious function would be regarded as being tantamount to death. (2) There are two foci to Lipuma's efforts in advancing this definition of death. The first is to show that an irreversible loss of conscious function is tantamount to a loss of personhood and thus, equivalent to death. The second is to show that the application of CSD, which would in fact sedate a patient to unconsciousness, is an irreversible process. We have already refuted Lipuma's assertions against the reversibility criterion and will now address the issues pertaining to defining death on the basis of an irreversible loss of consciousness and the wider practical considerations of this framework.

There is significant data to suggest that contrary to Lipuma's belief that, once applied, sedation levels will be stable. Barbato revealed that there is a great variation in the levels of sedation and levels of consciousness among iatrogenic, deeply sedated patients. ${ }^{(30)}$ These findings are further validated by data suggesting that even patients in persistent vegetative states and minimally conscious states manifest variations in consciousness levels when studied using positron emission tomography-computed tomography and electroencephalograms. ${ }^{(30,37-40)}$ Attempting to establish an irreversible loss of consciousness, much less a stable level of unconsciousness required for the determination of brain death, becomes technically difficult. ${ }^{24,34-43}$

This is particularly so when changes in pharmacokinetics and efficacy of medications used in the treatment of conditions such as delirium, epilepsy, schizophrenia and pain can affect levels of sedations. Therefore, there is no reason to overturn the Academy of Medical Royal Colleges' 2008 Code of Practice for the Diagnosis and Confirmation of Death, which states that "the definition of death should be regarded as the irreversible loss of the capacity for consciousness, combined with irreversible loss of the capacity to breathe."(44)

\section{TRIAD OF PERSONHOOD-RELATED CONSIDERATIONS}

The primacy of conscious function to conceptions of personhood sits at the core of Lipuma's higher brain function definition of death, yet it is barely defended. While authors such as Harris, ${ }^{(45)}$ Fletcher, ${ }^{(46)}$ and Rich $^{(47)}$ expound the primacy of conscious function, self-awareness, the ability to appreciate one's existence, and the ability to cogitate and to determine one's own fate as the central facets of conceptions of personhood, it is Lipuma ${ }^{(2)}$ who equates a loss of personhood with a determination of death. ${ }^{(45-50)}$ Reading Lipuma's paper, it would appear that he regards a consciousness-defined conception of personhood to be the 'right' way of conceiving personhood. ${ }^{(2)}$ It is unclear as to whether this position is based on the belief that a consciousnessdefined conception of personhood is the most morally, socially and/or practically justifiable position, or whether Lipuma believes that a consciousness-driven perspective of personhood is the most clinically relevant position. We will consider each of these positions.

To begin with, the primacy afforded to a consciousnessdefined conception of personhood is not widely accepted. Authors such as Nelson have adopted a Judeo-Christian view of personhood, which proposes that personhood is inherent to all humans by virtue of their divine connection with God. ${ }^{(51)}$ Lamb and Fan suggest that personhood within the Hindu and Confucian perspectives are rooted within the relational ties an individual shares with his or her families. ${ }^{(52,53)}$ This relational concept of personhood defined by relational ties between family members is also evident in other religions and societies throughout the world. ${ }^{(54-58)}$ However, Kitwood and Buron suggest that a combination of relational and social elements contribute to individual conceptions of personhood within the dementia setting, while Bishop Merrill's study of American students suggests that there is a wider combination of individual, relational and innate elements to personalised definitions of personhood. ${ }^{(59-61)}$ Krishna et al's and Alsuwaigh and Krishna's clinically evidenced Ring Theory of Personhood (Ring Theory), which was derived from data extracted from interviews with Singaporean oncology and palliative care patients on their views of their personhood, suggests 


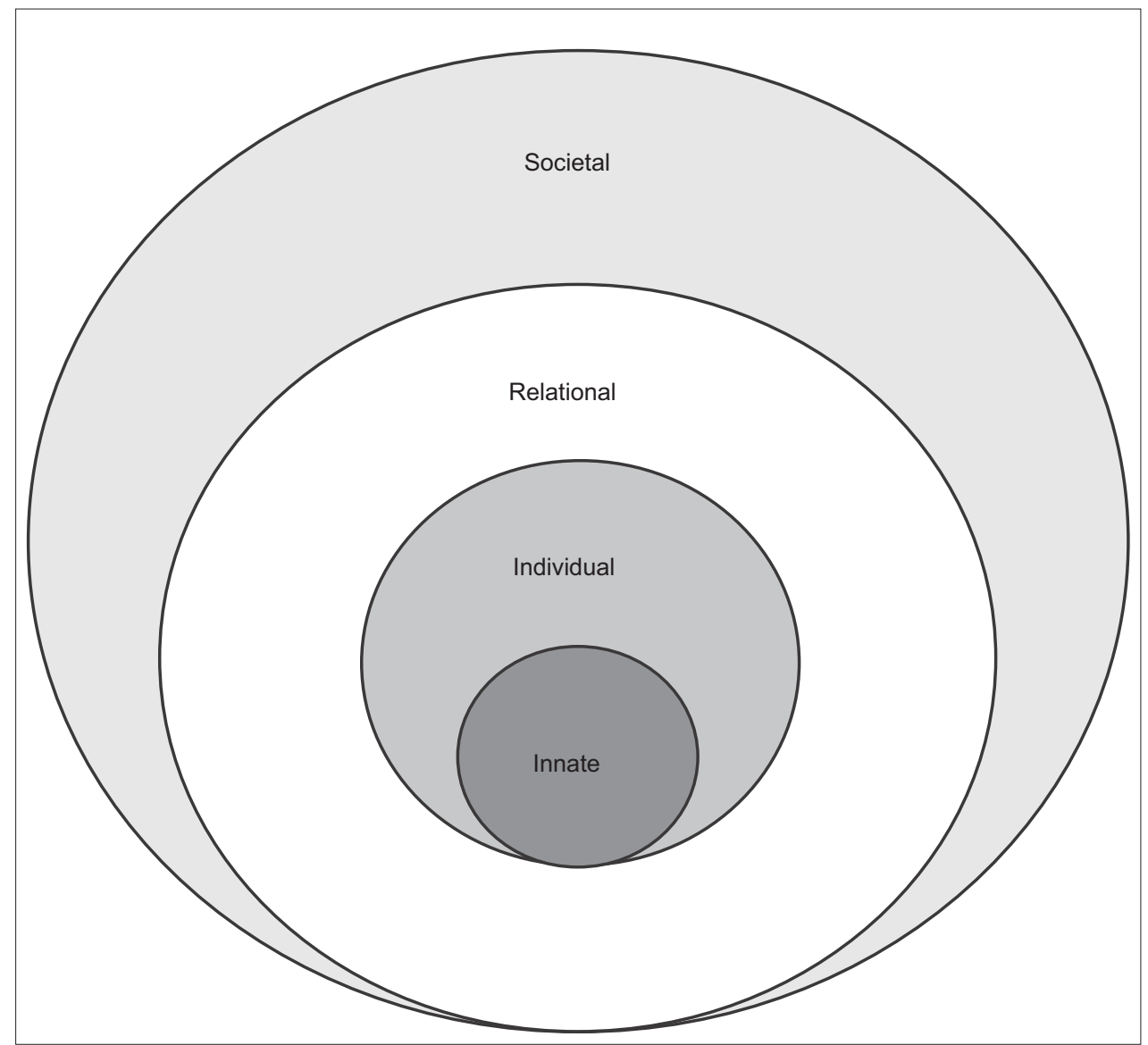

Fig. 1 Diagram shows the Ring Theory of Personhood, reproduced with permission from Alsuwaigh. ${ }^{(66)}$

that there are four essential elements to personhood (Fig. 1): Innate, Individual, Relational and Societal Personhoods. ${ }^{(62-66)}$

Innate Personhood arises by virtue of an individual's connection with God, as a result of being alive, having a human form, and/or as a result of familial, societal and relational ties. Individual Personhood revolves around conscious function and contains the individual's personality and behavioural characteristics. The Ring Theory posits that it is the individual with whom the patient shares strong personal bonds that endows them with Relational Personhood; it is these relational ties with individuals within this ring that preserve the individual characteristics of the incapacitated patient in a manner that the patient feels is most in keeping with his or her individuality. Societal Personhood, which represents the outermost ring of the Ring Theory, is derived from the bonds and relationships that are not significant enough to be considered within the Relational ring. Individuals within the Societal ring, comprising colleagues, acquaintances and business contacts, endow the patient with a 'general' or societally accepted view of personhood. ${ }^{(62-66)}$

While drawn from a Singaporean setting, the Ring Theory is expected to find acceptance even among the wider Asian, European and American populations, ${ }^{(17,61-82)}$ as suggested by prevailing data. Importantly, the Ring Theory is believed to better capture the manner in which conceptions of personhood evolve over time and circumstances. ${ }^{(62-66)}$ Echoing Krishna and Kwek's case study findings, ${ }^{\left({ }^{(83)}\right.}$ Krishna and Alsuwaigh's study revealed that most palliative care patients placed more importance on their spirituality and legacy whilst reducing the importance of their conscious function as they progressed along their illness journey. ${ }^{(62)}$ This increase in the relative importance of their respective Innate and Relational dimensions of personhood at the cost of their respective Individual ring is in keeping with data from Japan, the United States, Hong Kong and the Nordic nations, where similar evolutions in spiritual, social and individual beliefs and values have been documented. ${ }^{(84-86)}$ This wider reflexive concept of personhood highlights the rich tapestry of social, biological and spiritual bonds that exist between individuals irrespective of their conscious functioning. ${ }^{(62)}$ It also better contends with the evolution in goals of care and personal values and beliefs, as described in Krishna and Kwek's account of evolving concepts of personhood seen in the last months of life. ${ }^{(83)}$

\section{CONCLUSION}

Dismissal of each aspect of the personhood triad and the practical triumvirate overturns Lipuma's efforts to equate CSD to PAS/E. Yet, Lipuma's efforts highlight two key points. Firstly, the palliative medicine community can no longer regard CSD simply as a small part of the practice of legitimate end-of-life care. Rather, the impact of Lipuma's paper and other discussions in the media point to its wider impact on end-of-life care. As in Singapore and many nations such as Sri Lanka, Malaysia, Cambodia and Myanmar, the application and thus, validity and acceptability of CSD represent part of a wider referendum on the practice of palliative medicine itself. This shows CSD to be an entwined facet of the speciality 
that, if not effectively delineated, will compromise patient care and bring the palliative medicine speciality into disrepute.

While it is clear that Lipuma did not intend to comment on the practice of palliative medicine, his position-albeit largely based on philosophical ruminations and poorly contextualised empirical, clinical and societal data-has certainly stirred concerns in some quarters, over both the role of CSD and palliative medicine. It emphasises the importance of education of the general public and healthcare professionals regarding the differences between the practices of CSD and PAS/E, and the role of palliative medicine. Part of this process requires careful definition of the practice of deep continuous sedation in endof-life care, which considers sociocultural implications of the practice and sets it apart from the 'routine' use of opioids for the treatment of pain and dyspnoea in end-of-life care, and the use of sedatives for the treatment of confusion, delirium and agitation in end-of-life care.

Finally, palliative medicine should be indebted to Lipuma, for issuing a call to palliative medicine not only to be proactive in explaining its practice, but also in being vigilant and responsive to efforts to paint aspects of its practice in a less than complimentary light, when the toll may be, more than palliative medicine's reputation, patient care and family distress.

\section{ACKNOWLEDGEMENTS}

The authors would like to dedicate this paper to Dr Deborah Watkinson, National Cardiac Centre Singapore, and Duke-NUS Medical School, Singapore, for her significant contributions to this paper. Sadly, she passed away before this project could be completed.

\section{REFERENCES}

1. Battin M. Terminal sedation: pulling the sheet over our eyes. Hastings Cent Rep 2008; 5:27-30.

2. Lipuma $\mathrm{SH}$. Continuous sedation until death as physician-assisted suicide/ euthanasia: a conceptual analysis. J Med Philos 2013; 38:190-204.

3. Radha Krishna LK, Poulose JV, Tan BS, Goh C. Opioid use amongst cancer patients at the end of life. Ann Acad Med Singapore 2010; 39:790-7.

4. Krishna L, Capps B. Opioid use at the end of life: working out the physician's intentions. Indian J Med Ethics 2011; 8:39-41.

5. Radha Krishna LK, Poulose JV, Goh C. The use of midazolam and haloperidol in cancer patients at the end of life. Singapore Med J 2012; 53:62-6.

6. Krishna L, Ho S. Reapplying the "Argument of Preferable Alternative" within the Context of Physician-Assisted Suicide and Palliative Sedation. Asian Bioeth Rev 2015; 7:62-80.

7. Lo B, Rubenfeld G. Palliative sedation in dying patients: "we turn to it when everything else hasn't worked". JAMA 2005; 294:1810-6.

8. Hartocollis A. Hard choice for a comfortable death: drug-induced sleep. The New York Times 2009 Dec 27; Sect A1.

9. Krishna L. Doctrine of Double Effect [DDE] need not be invoked for the opioids at the end of life. Abstract of presentation in the session "Policy and End of Life Decisions". End of Life Decisions: Ethics in clinical practice, research and policy. XI Annual Swedish Symposium on Biomedicine, Ethics and Society, 8-9 June 2009. Available at: http://www.crb.uu.se/ symposia/2009/abstracts/Krishna-090609-EndOfLifeDecisions.pdf.

10. Allmark P, Cobb M, Liddle BJ, Tod AM. Is the doctrine of double effect irrelevant in end-of-life decision making? Nurs Philos 2010; 11:170-7.

11. Krishna LK, Chin J. Terminal sedation within the duty of palliative care. Asian Bioeth Rev 2011; 3:201-15.

12. Boyle J. Medical ethics and double effect: the case of terminal sedation. Theor Med Bioeth 2004; 25:51-60.

13. Mclntyre A. The double life of double effect. Theor Med Bioeth 2004; 25:61-74.
14. Mcintyre A. Doctrine of Double Effect. In: Zalta EN, eds. The Stanford Encyclopaedia of Philosophy (Winter 2014 Edition). Available at: http:// plato.stanford.edu/entries/double-effect/. Accessed January 19, 2015.

15. Rys S, Deschepper R, Mortier F, et al. The moral difference or equivalence between continuous sedation until death and physician-assisted death: word games or war games?: a qualitative content analysis of opinion pieces in the indexed medical and nursing literature. J Bioeth Inq 2012; 9:171-83.

16. Tannsjo T. Terminal Sedation: a substitute for euthanasia? In: Tannsjo T, eds. Terminal sedation - Euthanasia in disguise. Boston: Kluwer Academic Publishers, 2004:15-30.

17. Morita T, Tsuneto S, Shima Y. Proposed definitions of terminal sedation. Lancet 2001; 358:335-6.

18. Rietjens JA, Hauser J, van der Heide A, Emanuel L. Having a difficult time leaving: experiences and attitudes of nurses with palliative sedation. Palliat Med 2007; 21:643-9.

19. Krishna LK. Addressing the Concerns Surrounding Continuous Deep Sedation in Singapore and Southeast Asia: A Palliative Care Approach. J Bioeth Inq 2015; 12:461-75.

20. Sykes N, Thorns A. The use of opioids and sedatives at the end of life. Lancet Oncol 2003; 4:312-8.

21. Wilcock A, Chauhan A. Benchmarking the use of opioids in the last days of life. J Pain Symptom Manage 2007; 34:1-3.

22. Krishna L. Consent in terminal sedation. Indian J Med Ethics 2010; 7:161-4.

23. Hospice \& Palliative Care Federation of Massachusetts. Palliative Sedation Protocol [online]. Available at: http://hospicefed.org/files/reports/pal_sed_ protocol.pdf. Accessed December 10, 2014.

24. Bruce SD, Hendrix CC, Gentry JH. Palliative sedation in end-of-life care. J Hosp Palliat Nurs 2006; 8:320-7.

25. Claessens P, Menten J, Schotsmans P, Broeckaert B. Level of consciousness in dying patients. The role of palliative sedation: a longitudinal prospective study. Am J Hosp Palliat Care 2012; 29:195-200.

26. Hui D, dos Santos R, Chisholm G, et al. Clinical signs of impending death in cancer patients. Oncologist 2014; 19:681-7.

27. Kohara H, Ueoka H, Takeyama H, Murakami T, Morita T. Sedation for terminally ill patients with cancer with uncontrollable physical distress. J Palliat Med 2005; 8:20-5.

28. Mercadante S, Porzio G, Valle A, Aielli F, Casuccio A; Home Care-Italy Group. Palliative sedation in patients with advanced cancer followed at home: a prospective study. J Pain Symptom Manage 2013; 47:860-6.

29. Porzio G, Aielli F, Verna L, et al. Efficacy and safety of deep, continuous palliative sedation at home: a retrospective, single-institution study. Support Care Cancer 2010; 18:77-81.

30. Barbato M. Bispectral index monitoring in unconscious palliative care patients. J Palliat Care 2001; 17:102-8.

31. Good P, Cavenagh J, Mather M, Ravenscroft P. Medically assisted hydration for adult palliative care patients. Cochrane Database Syst Rev 2008; (2):CD006273.

32. Committee on National Guideline for Palliative Sedation. Royal Dutch Medical Association (KNMG). Guideline for Palliative Sedation. http://www.knmg.nl/web/file?uuid=d57c9dec-49d343a2-9c4d-1b15005c615c\&owner=a8a9ce0e-f42b-47a5-960ebe08025b7b04\&contentid=66977. Accessed December 17, 2015.

33. Cherny NI, Radbruch L; Board of the European Association for Palliative Care. European Association for Palliative Care (EAPC) recommended framework for the use of sedation in palliative care. Palliat Med 2009; 23:581-93.

34. Krishna LK, Chin J. Palliative sedation within the duty of palliative care within the Singaporean clinical context. Asian Bioeth Rev 2011; 3:207-15.

35. Anquinet L, Rietjens JA, Van den Block L, Bossuyt N, Deliens L. General practitioners' report of continuous deep sedation until death for patients dying at home: a descriptive study from Belgium. Euro J Gen Pract 2011; $17: 5-13$

36. Swart SJ, Brinkkemper T, Rietjens JA, et al. Physicians' and nurses' experiences with continuous palliative sedation in the Netherlands. Arch Intern Med 2010; 170:1271-4.

37. Barrientos-Vega R, Mar Sánchez-Soria M, Morales-García C, et al. Prolonged sedation of critically ill patients with midazolam or propofol: impact on weaning and costs. Crit Care Med 1997; 25:33-40.

38. Haenggi M, Ypparila-Wolters H, Bieri C, et al. Entropy and bispectral index for assessment of sedation, analgesia and the effects of unpleasant stimuli in critically ill patients: an observational study. Crit Care 2008; 12:R119.

39. Miyake W, Oda Y, Ikeda Y, et al. Electroencephalographic response following midazolam-induced general anesthesia: relationship to plasma 
and effect-site midazolam concentrations. J Anesth 2010; 24:386-93.

40. Brinkkemper T, van Norel AM, Szadek KM, et al. The use of observational scales to monitor symptom control and depth of sedation in patients requiring palliative sedation: a systematic review. Palliat Med 2013; 27:54-67.

41. Ogilvie MP, Pereira BM, Ryan ML, et al. Bispectral index to monitor propofol sedation in trauma patients. J Trauma 2011; 71:1415-21.

42. Lehembre R, Gosseries O, Lugo Z, et al. Electrophysiological investigations of brain function in coma, vegetative and minimally conscious patients. Arch Ital Biol 2012; 150:122-39.

43. Massimini M, Ferrarelli F, Sarasso S, Tononi G. Cortical mechanisms of loss of consciousness: insight from TMS/EEG studies. Arch Ital Biol 2012; 150:44-55.

44. Academy of Medical Royal Colleges. A code of practice for the diagnosis and confirmation of death. Available at: www.aomrc.org.uk/doc_view/42 a-code-of-practice-for-the-diagnosis-and-confirmation-of-death. Accessed November 22, 2014

45. Harris J. Consent and end of life decisions. J Med Ethics 2003; 29:10-5.

46. Fletcher J. Humaneness. Humanhood: Essays in Biomedical Ethics. Buffalo, NY: Prometheus Books, 1979: 12-6.

47. Rich BA. Postmodern personhood: a matter of consciousness. Bioethics 1997; 11:206-16

48. Farah MJ, Heberlein AS. Personhood and neuroscience: naturalizing or nihilating? Am J Bioeth 2007; 7:37-48.

49. Juth N, Lindblad A, Lynöe N, Sjöstrand M, Helgesson G. European Association for Palliative Care (EAPC) framework for palliative sedation: an ethical discussion. BMC Palliat Care 2010; 9:20.

50. Materstvedt LJ. Intention, procedure, outcome and personhood in palliative sedation and euthanasia. BMJ Support Palliat Care 2012; 2:9-11.

51. Nelson G. Maintaining the integrity of personhood in palliative care. Scottish J Healthcare Chaplaincy 2000; 3:34-9.

52. Lamb S. The making and unmaking of persons: notes on aging and gender in North India. Ethos 1997; 25:279-302.

53. Fan R. Reconsidering surrogate decision making: Aristotelianism and Confucianism on ideal human relations. Philos East West 2002; 52:346-72.

54. Hamon RR, Blieszner R. Filial responsibility expectations among adult child-older parent pairs. J Gerontol 1990; 45:P110-2.

55. Hillcoat-Nallétamby S. Exploring intergenerational relations in a multicultural context: the example of filial responsibility in Mauritius. J Cross Cult Gerontol 2010; 25:71-86.

56. Khalaila R, Litwin H. Does filial piety decrease depression among family caregivers? Aging Ment Health 2011; 15:679-86.

57. Stuifbergen MC, van Delden JJ. Filial obligations to elderly parents: a duty to care? Med Health Care Philos 2011; 14:63-71.

58. Aires M, Weissheimer AM, Rosset I, et al. Transcultural adaptation of filial responsibility interview schedule for Brazil. Int Nurs Rev 2012; 59:266-73.

59. Kitwood T. Dementia Reconsidered: the Person Comes First. Buckingham: Open University Press, 1997.

60. Buron, B. Levels of personhood: a model for dementia care. Geriatr Nurs 2008; 29:324-32.

61. Bishop Merrill S. Defining Personhood: towards the Ethics of Quality in Clinical Care. Amsterdam-Atlanta: Rodopi, 1998.

62. Radha Krishna LK, Alsuwaigh R. Understanding the fluid nature of personhood - the ring theory of personhood. Bioethics 2015; 29:171-81.

63. Krishna LK. Personhood within the context of sedation at the end of life in Singapore. BMJ Case Rep 2013; pii: bcr2013009264.

64. Radha Krishna LK. Accounting for personhood in palliative sedation: the Ring Theory of Personhood. Med Humanit 2014; 40:17-21.

65. Krishna LK, Alsuwaigh R, Miti PT, et al. The influence of the family in conceptions of personhood in the palliative care setting in Singapore and its influence upon decision making. Am J Hosp Palliat Care 2014; 31:645-54.

66. Alsuwaigh R. How do English-speaking Cancer Patients Conceptualise Personhood? Ann Acad Med Singapore 2015; 44:207-17.

67. Campos B, Schetter CD, Abdou CM, et al. Familialism, social support, and stress: positive implications for pregnant Latinas. Cultur Divers Ethnic Minor Psychol 2008; 14:155-62.

68. Lim JW. Communication, coping, and quality of life of breast cancer survivors and family/friend dyads: a pilot study of Chinese-Americans and Korean-Americans. Psychooncology 2014; 23:1243-51.

69. Sittisombut S, Inthong S. Surrogate decision-maker for end-of-life care in terminally ill patients at Chiang Mai University Hospital, Thailand. Int J Nurs Pract 2009; 15:119-25.

70. Cheng KY, Ming T, Lai A. Can familialism be justified? Bioethics 2012; 26:431-9.

71. Tsai DF. How should doctors approach patients? A Confucian reflection on personhood. J Med Ethics 2001; 27:44-50.

72. Tsai DF. Ancient Chinese medical ethics and the four principles of biomedical ethics. J Med Ethics 1999; 25:315-21.

73. Chiu TY, Hu WY, Huang HL, Yao CA, Chen CY. Prevailing ethical dilemmas in terminal care for patients with cancer in Taiwan. J Clin Oncol 2009; 27:3964-8.

74. Chan EA, Cheung K, Mok E, Cheung S, Tong E. A narrative inquiry into the Hong Kong Chinese adults' concept of health through their cultural stories. Int J Nurs Stud 2006; 43:301-9

75. Kou EC. Some Observations on the Study of Family Change in Singapore. In: Kou EC, Wong AK, eds. The Contemporary Family in Singapore: Structure and Change. Singapore: Singapore University Press, 1979: 3-17.

76. Low JA, Kiow SL, Main N, et al. Reducing collusion between family members and clinicians of patients referred to the palliative care team. Perm J 2009; 13:11-5.

77. Yamagishi A, Morita T, Miyashita M, et al. The care strategy for families of terminally ill cancer patients who become unable to take nourishment orally: recommendations from a nationwide survey of bereaved family members' experiences. J Pain Symptom Manage 2010; 40:671-83.

78. Lai DW, Surood S. Chinese health beliefs of older Chinese in Canada. J Aging Health 2009; 21:38-62.

79. Garanis-Papadatos T, Katsas A. The milk and the honey: ethics of artificial nutrition and hydration of the elderly on the other side of Europe. J Med Ethics 1999; 25:447-50

80. Padela AI, Malik AY, Curlin F, De Vries R. [Re]considering Respect for Persons in a Globalizing World. Dev World Bioeth 2015; 15:98-106.

81. Oh DY, Kim AE, Lee $\mathrm{CH}$, et al. Discrepancies among patients, family members, and physicians in Korea in terms of values regarding the withholding of treatment from patients with terminal malignancies. Cancer 2004; 100:1961-6.

82. Oh do Y, Kim JH, Lee $\mathrm{SH}$, et al. Artificial nutrition and hydration in terminal cancer patients: the real and the ideal. Support Care Cancer 2007; 15:631-6.

83. Krishna LK, Kwek SY. The changing face of personhood at the end of life: The ring theory of personhood. Palliat Support Care 2005; 13:1123-9.

84. Rabow MW, Dibble SL, Pantilat SZ, McPhee SJ. The comprehensive care team: a controlled trial of outpatient palliative medicine consultation. Arch Intern Med. 2004; 164:83-91.

85. Karlsson M, Friberg F, Wallengren C, Ohlén J. Meanings of existential uncertainty and certainty for people diagnosed with cancer and receiving palliative treatment: a life-world phenomenological study. BMC Palliat Care 2014; 13:28

86. Cheng ST, Chan AC. Filial piety and psychological well-being in well older Chinese. J Gerontol B Psychol Sci Soc Sci 2006; 61:P262-9. 